\title{
Kerk en kultuur - 'n godsdiens-teologiese perspektief
}

P J van der Merwe

Departement Godsdiens- en Sendingwetenskap (Afd A)

Universiteit van Pretoria

\begin{abstract}
Church and culture - a religio-theological perspective

The intimate and symbiotic relationship between religion and culture postulated by various sociologists of religion is accepted as backdrop for an elaboration of the principle of the church being in the world but not of it. The question whether a peoples church 'volkskerk' has any special cultural responsibilities is also addressed. Finally it is contended that modern, secularised culture is controlled by a civil ideology akin to civil religion.
\end{abstract}

\section{INLEIDING}

Die aanleiding tot hierdie artikel is eerstens die projek van die Fakulteit Teologie (Afd A), Universiteit van Pretoria, or die verhouding kerk en kultuur, en tweedens die vraag of die kerk 'n kultuurtaak het wat as studie-opdrag deur die vier-en-sestigste Algemene Kerkvergadering van die Nederduitsch Hervormde Kerk aan die Dosentevergadering van dieselfde fakulteit opgedra is (AKV 1995:62).

Die vraag van die Algemene Kerkvergadering lyk met die eerste oogopslag na 'n onsinnige een. Kultuur is immers deel van menswees. Die kerk het nie alleen 'n kersteningstaak teenoor die gemeenskaps- en volkslewe nie, maar is ook op meer as een wyse betrokke by die menswees van die lidmate van die kerk. So gesien is die saak reeds beslis. Daarom die antwoord wat so vinnig uit die vergadering gekom het dat die kerk inderdaad 'n kultuurtaak het (AKV 1995:66).

Dit kan egter kwalik aanvaar word dat die tyd van die Algemene Kerkvergadering en die Dosentevergadering met onsinnige vrae gemors sal word. Daarom moet gevra word of daar nie 'n ander vraag agter hierdie een lê nie. Dit is een van die sake wat oorweeg moet word.

In hierdie artikel wil ek dus die begrip 'kultuur' oordink en verder oorweeg hoe kerkwees daardeur geraak word, die kerk se verantwoordelikheid teenoor kultuur en volk, en laastens die probleem van burgerlike godsdiens binne die verband van kerk en kultuur. 


\section{DIE BEGRIP KULTUUR EN AANVERWANTE BEGRIPPE}

Gewoonlik is dit een van die sekondêre (en beperkte) betekenisse van kultuur wat in die populêre gedagte voorop staan, naamlik as beskrywing van 'n gemeenskap se intellektuele en artistieke skeppings en prestasies. Die algemene indruk is dus dat kultuur 'n saak is waarby slegs ' $n$ klein groep in die samelewing belang het.

Die primêre betekenis van die term kultuur beskryf egter die totale kompleks van taal, lewensuitkyk, gebruike, lewenswaardes, lewenspatroon, skeppinge, uitvindings en dies meer van ' $n$ bepaalde groep mense of van 'n bepaalde tydsgewrig. Dit volg daaruit dat die mens ' $n$ kultuurwese is. Die mens is kultuurskepper en self ook kultuurproduk. Daar is nie 'n enkele aspek van die mens se lewe wat nie op een of ander wyse met kultuur te doen het nie. Om van kultuur te praat, is om van menswees (in individuele en gemeenskaplike sin) te praat.

Verskeie dissiplines in die groep van geesteswetenskappe en sosiale wetenskappe het direkte belang by die bestudering van kultuur. Die twee wat uitstaan, is Volkekunde (deesdae toenemend Antropologie genoem) en Sosiologie. Al die ander het egter ook op een of ander manier daarmee te doen, al word dit nie altyd besef of verreken nie.

Wanneer na 'n definisie van kultuur gevra word, moet die dissiplinêre invalshoek van die een wat die antwoord gee, in aanmerking geneem word. Soveel invalshoeke bring soveel perspektiewe op kultuur na vore. Die volgende kort oorsig van sosiologiese en volkekundige posisies gee iets daarvan weer.

\subsection{Kort oorsig}

Sosioloë is oor die algemeen geneig om 'n redelik abstrakte beskouing van kultuur te hê. Hulle rig hulle aandag op kultuurpatrone wat die individuele en sosiale lewe struktureer, en gebruik as verwysingsgroep enige groepering wat die doel van die studie dien.

- Wuthnow (1984:3) bied die volgende definisie aan: Kultuur is menslike gedrag soos uitgedruk in simbole.

- Peter Berger beskou kultuur (volgens Wuthnow 1984:25) as 'n allesomvattende, sosiaal saamgestelde wêreld van betekenisse wat uit subjektiewe en intersubjektiewe ervarings afgelei is. Dit verleen betekenis en sin, maar dui ook die grense vir betekenis en sin aan.

- LeVine (Shweder 1984:67): 'Culture (is) a shared organization of ideas that includes the intellectual, moral, and aesthetic standards prevalent in a community and the meanings of communicative actions'. 
Geertz (1973:89) sê: 'Culture (is) an historically transmitted pattern of meanings embodied in symbols, a system of inherited conceptions expressed in symbolic form by means of which men communicate, perpetuate, and develop their knowledge about and attitudes towards life'.

Uit hierdie beskouings is dit dan duidelik dat kultuur altyd 'n sosiale assosiasie het. Die sosiale verwysing kan na samelewing, volk, gemeenskap of enige sosiale groep wees wat vir die metodologiese invalshoek van die navorser dienlik geag word.

Volkekundiges het ' $n$ eie beskouing en benadering van kultuur. Hulle sluit materiële kultuurprodukte daarby in, terwyl sommiges 'n begrip soos etnisiteit ook wesenlik ag. Hier word in die besonder gekyk na die standpunte van die bekende volkekundiges van Pretoria, P J en R D Coertze, wat oor meer as veertig jaar 'n groot invloed op die denke van die Nederduitsch Hervormde Kerk uitgeoefen het.

- 'n Handboek wat aan baie predikante in die Nederduitsch Hervormde Kerk bekend is (Coertze 1961:12) het die volgende oor Volkekunde en kultuur te sê: Volkekunde bestudeer kultuur as eenheidslewenspatroon, dit wil sê as volke se kultuurpatrone. Sulke kultuurpatrone vertoon verskeie fasette wat vervlegd voorkom. Die deel van die Volkekunde wat hieraan aandag gee, is die Kulturele Volkekunde/Antropologie. Dit fokus veral op die volgende:

* Die verskeidenheid kulture wat oor die wêreld aangetref word.

* Die klassifikasie van hierdie kulture volgens beginsels wat uit die studie self voortspruit.

* Die verskeidenheid faktore wat verantwoordelik is vir die bestaan van kulture wat van mekaar verskil.

* Die wyse waarop kultuur verander en die faktore wat daarvoor verantwoordelik is of daarmee in verband gebring kan word.

* Die betekenis van kultuur in die lewe van mense en watter uitwerking kultuurveranderinge op die betrokke mense het.

* Die mens as produk van kultuur, sowel na uiterlike as innerlike lewe.

* Hiernaas lees ons in dieselfde boek (p 31): 'Kultuur as volkekundige begrip dui aan alles wat deur die mens in sy verskillende volksverbande tot stand gebring is en vorm die resultaat van die skeppende werksaamheid van die mens'. 
Coertze gaan voort deur die volgende oor kultuur te sê:

Die strukturele gestalte van ... 'n volk lê dan opgesluit in sy kultuurpatroon. Daarom is ' $n$ volk en sy kultuur eintlik 'n tweeledige eenheid .... Kultuur is derhalwe ... die uiterlike en innerlike lewensgestalte van 'n volk, soos dit binne 'n bepaalde omgewing vorm aangeneem het.

(Coertze 1961:35)

R D Coertze het in 'n memorandum aan 'n studiekommissie van die Nederduitsch Hervormde Kerk die volgende oor kultuur gesê:

Die kultuurpatroon waarna verwys is, omvat 'n reeks van ten minste fasette of universele aspekte waarin elke volk eie besondere variasies vertoon, hoe klein hulle ook mag wees. Hierdie vyftien fasette is die volgende: ekonomiese organisasie, tegniese skeppinge, voortplantingstelsel, sosiale organisasie, regeringstelsel, militêre stelsel, regstelsel, judisiële stelsel, religie, kennissisteem, kunsskeppinge, opvoedingstelsel, taal, waardesisteem, spele en ontspanning ...

Die lewenspatroon van 'n volk word deur elke opgroeiende volkslid deur 'n langsame opvoedingsproses verwerf. Die waarde-oordele van sy mense word in hierdie proses in sy persoonlikheid veranker .... Elke nuwe kultuuraanbod wat deur eie skepping ontstaan of van buite oorgeneem word, word eers deel van die volkseie as dit aanvaar en by die bestaande lewenspatroon ingeweef word ....

(Coertze 1980:159)

In 1996 spreek die Coertzes hulle soos volg oor kultuur uit:

Alle skeppinge wat die mens as komplekse lewende wese binne etnieè in 'n proses van selfhandhawing in (aanpassing by) 'n komplekse omgewing tot stand bring. Dit hou in: kultivering van die mens self en van sy omgewing, asook die skepping van alle apparaat, metodes en tegnieke waarmee en waarvolgens kultivering plaasvind. Kultuur bestaan dus as die geykte, samehangende lewenspatroon van 'n etnos en word van die een geslag na die volgende deur 'n proses van enkulturasie oorgedra. 
Binne die Amerikaanse kultuurstreekbenadering en die Duits-Oostenrykse kultuurkringbenadering is die begrip kultuur areagebonde en berus op die coreenstemmende verspreiding van kultuurelemente en kultuurkomplekse. Binne die Britse sosiale antropologie verwys kultuur na 'n sisteem van waardes, idees en gedrag by 'n sosiale groepering wat die navorser vir die doel van sy studie as sodanig afbaken.

(Coertze 1996:164vv)

Die volkekundige standpunt wat deur die Coertzes verteenwoordig word, wil kultuur dus as 'n etniese verskynsel bestudeer. Dit beteken nie dat kultuur nét etnies is nie, maar dat hulle metodologiese invalshoek hulle so 'n dissipline ople. Iemand wat dit nie begryp nie, kan egter maklik onder die indruk kom dat kultuur as 'n etniese verskynsel verstaan móét word en dat ' $n$ verwysing na kultuur vanself ' $n$ verwysing na volk is.

Soos vroēer opgemerk, maak die invalshoek 'n groot verskil wanneer daar oor kultuur nagedink word. Dit bring ons teng by die poging om die projek van die Fakulteit Teologie (Afd A) en die studie-opdrag van die Algemene Kerkvergadering te kombineer. Eersgenoemde benader kultuur as 'n menslike verskynsel, met die hele spektrum van moontlike perspektiewe daarop. Laasgenoemde se invalshoek kan bepaal word deur vas te stel wat die oorspronklike vraers (dit is die Kommissie vir die Herskrywing van die Kerkwet) in gedagte gehad het.

Die vraag van die Algemene Kerkvergadering

Inligting wat van prof $\mathbf{S} \mathbf{J}$ Botha, voorsitter van die Kommissie vir die Herskrywing van die Kerkwet van die Nederduitsch Hervormde Kerk, verkry is (1996-05-29), stel dit bo alle twyfel dat genoemde vraag uitgegaan het van 'n verband tussen kultuur en volk. Die vraag het in die debat oor kerk en onderwys na vore gekom en moet in verband gebring word met ander vrae soos: 'Moet die Kerk hom steeds beywer vir Christelikvolkseie onderwys'? (Antwoord: 'Die Kerk moet steeds beywer vir Christelik-volkseie onderwys') en: 'Behoort daar in die Kerkorde iets oor volkseie opvoeding en onderwys te staan'? (Antwoord: 'Die Kerkorde sal oor volkseie opvoeding en onderwys moet handel'). Kultuur kan dus in hierdie verband as sinoniem vir volkseie opgeneem word.

Dit lyk dus nie onbillik om die vraag van die Algemene Kerkvergadering te interpreteer as 'n vraag of die Nederduitsch Hervormde Kerk wat homself as volkskerk sien, 'n taak teenoor die volk en volkseie het nie. Daarop kan gevra word: watter soort taak? Om die volk en volkseie in stand te help hou of voortdurend te kersten? Dit is die soort vrae wat later oorweeg sal word wanneer daar oor die volkskerk binne die verband van hierdie vraagstelling besin sal word. 


\section{KULTUUR DIEPER BETRAG}

Een van die moderne geleerdes wat die dieper dimensies van kultuur omvangryk deurdink het en moontlik die grootste bydrae tot hedendaagse kultuurteorie gelewer het, is die Amerikaanse sosioloog, Peter L Berger (1929- ). Hy is 'n eklektiese denker wat daarin slaag om 'n distillaat van verskeie voorgangers en tydgenote se denke in 'n oortuigende, nuwe sintese aan te bied (Wuthnow 1984:72').

Soos baie ander voor hom, sê Berger dat mense organismies nie 'n werklikheidsoriëntasie het nie, maar dit moet ontwikkel. Daarom is dit noodsaaklik dat mense deur 'n lang grootword- en opvoedingsproses moet gaan. Wat aanvanklik in sy onguns tel, blyk later egter 'n bate te wees, aangesien dit aan die mens 'n openheid teenoor die wêreld verleen. Dit beteken dat die mens nie in een werklikheidsoriëntasie vasgevang is nie, maar deurlopend by die werklikheid moet aanpas.

Dit gaan gepaard met werklikheidskonstruksie. Die mens skep vir hom/haar 'n teoretiese model van die werklikheid. Die mens is self die oriëntasiepunt daarvan, omdat hy/sy ' $n$ intensionele wese is. Werklikheidskonstruksie is ook kultuurbou.

Aan die ancier kant is daar wel 'n aangebore menslike eienskap wat menslike aanpassing by die werklikheid beïnvloed en dit is dat die mens 'n sosiale wese is. Werklikheidskonstruksie is dus ook sosiale aktiwiteit. Kultuur is wesenlik sosiaal.

Berger is van mening dat die gekonstrueerde werklikheid 'n inherente en konstante dialektiek verteenwoordig. Daar is trouens sprake van twee dialektiese prosesse: enersyds tussen die self (of identiteit) en liggaam (of organisme), en andersyds tussen die self en die sosio-kulturele wêreld. Laasgenoemde onderskei hy in drie momente, naamlik eksternalisering, objektivering en internalisering.

Soos genoem, is werklikheidskonstruksie en kuluurbou 'n deurlopende proses. Solank daar mense of gemeenskappe is, gaan dit voort. Dit is egter ook ' $n$ sinsoekende en sinverlenende aktiwiteit. Sulke konstruksies word betekenisraamwerke - verstaan vind nie alleen neerslag in die konstruksies nie, maar word ook weer daaruit afgelei. Dit word verstaansraamwerke vir waarheid en nuwe kennis. Dit legitimeer waardes, beginsels en reëls (Wuthnow 1984:25).

Terwyl kultuur betekenis en sin verleen, dui dit ook die grense daarvan aan. Die individu word in 'n sekere mate toegelaat om nonkonformisties op te tree, maar ter wille van die stabiliteit van die gemeenskap word die waarheidskonsensus wat in kultuur neerslag vind, beskerm. Die gekonstrueerde werklikheid is en bly 'n kunsmatige werklikheid. Dit word dikwels onder spanning geplaas deur alternatiewe werklikheidservarings of deur krisiservarings. Wanneer die gekonstrueerde werklikheid so

1. Die samevatting en analise van Berger se denke deur Wuthnow (1984) word gevolg. 
onder druk kom, beteken dit dat die waarheid self onder druk kom, omdat die mens en die gemeenskap waarvan dit deel is, geen ander waarheid ken as die gekonstrueerde werklikheid nie.

Waarheid is 'n strategiese saak en daarom 'n belangrike strategiese aangeleentheid en instrument van mag. Dit word in die gemeenskap beheer deur geïnstitusionaliseerde strukture. Insigte oor aspekte van die werklikheid mag in beginsel korrek wees, maar word normaalweg nie as waar erken voordat die sosiale impak daarvan verreken is nie. In geval van krisisse kom hierdie stelsel onder druk en ervaar die gemeenskap nie alleen dat sy waarheidsverstaan bedreig word nie, maar sy eie bestaan ook.

Uiteraard is die werklikheid vatbaar vir verskeie verstaansmoontlikhede. Dit verklaar die veelheid van kulture, asook die innerlike pluraliteit kulture.

Tog is dit interessant dat Berger met 'n ontologiese prioriteit werk, dit wil sê dat voorrang gegee word aan die eksterne werklikheid, die 'wêreld van alledaagse praxis'. Volgens Wuthnow (1984:31) volg Berger die interpretatiewe metode van Alfred Schutz na. Schutz se model word deur hom soos volg opgesom:

* Mense lewe as individue in 'n lewenswêreld. Dit is 'n sfeer wat saamgestel word uit ervarings van die natuurlike omgewing, mensgemaakte dinge, gebeurtenisse en ander individue. Aangesien daar egter verskillende maniere van ervaar moontlik is (byvoorbeeld drome, hallusinasies en die teater), kom dit neer op 'n samestelling van veelvuldige werklikhede, alhoewel hy steeds aan die alledaagse lewenswerklikheid voorrang gee. Vanweë die sosiale aard van die alledaagse lewenswêreld is dit ook 'n intersubjektiewe wêreld. Daarteenoor maak die ander, enkelsubjektiewe ervaringswêrelde beperkte betekenisprovinsies uit.

* Ten einde beginsels en waardes van die gedeelde, intersubjektiewe, alledaagse lewenswerklikheid sosiaal werkbaar te maak, word die beginsel van abstraksie en tipifikasie toegepas. So kom 'n gemeenskaplike skat van kennis en ervaring tot stand wat aan die hand van bepaalde prioriteite en belange georganiseer word. Die belangrikste faktor bly egter die alledaagse pragmatiese motief.

Om saam te vat:

* Kultuur is die totaal van menslike produkte, sigbaar en onsigbaar. Dit is sosiaal en intersubjektief. Dit verwys na individue en die gemeenskap waarvan hulle deel is. 
* 'n Kultuurgemeenskap beskik oor identiteit en so ook die lede daarvan. Individuele identiteit is die gesosialiseerde self. Individuele identiteit bestaan uit persoonlike verwerking van groepwaardes en die identifisering van 'n eie plek en rol in die groep.

* Simbole en tekens is belangrik omdat hulle staan vir geobjektiveerde betekenisse en waardes. In kultuur speel hulle daarom 'n fundamentele rol. Die belangrikste kultuurelement is stellig taal. Dit is beide simbool, teken en instrument. Taal maak dit moontlik om ' $n$ intersubjektiewe werklikheid te konstrueer, om verlede en hede te oorbrug, om ervarings te deel wat amper nie mededeelbaar is nie.

* Nog 'n fundamentele element van kultuur is institusionalisering. Instellings en geobjektiveerde stelsels (sigbaar en onsigbaar) word deur die gemeenskap geskep of ontwikkel aan die hand van langdurige ervaring en is gerig op sekere herhalende situasies of behoeftes.

* Die kultuurgemeenskap word oorkoepel deur verskillende vlakke van teoretiese stelsels en instellings waardeur die werklikheid (insluitend die geskiedenis) ontsluit en verstaan word. Die hoogste hiervan is die simboliese universele verwysingsraamwerk (symbolic universe). Daarin word al die verskillende stelsels saamgebring en saamgevoeg. ' Die simboliese universele verwysingsraamwerk word beskryf teur mitologie, teologie, filosofie en wetenskap (Wuthnow 1984:48). Die betekenis wat aan genoemde elemente toegeken word, wissel van gemeenskap tot gemeenskap.

** Religie is ' $\mathrm{n}$ mensgemaakte konstellasie van betekenisse en waardes waardeur die heelal as heilige kosmos geprojekteer word. Dit bied aan die gemeenskap as geheel 'n 'sacred canopy'. Dit verteenwoordig die hoogste vorm van werklikheidskonstruksie. Religie as waardestelsel word in twee rigtings uitgespel: in mitologie en teologie. Eersgenoemde verteenwoordig die meer naiewe en populère konseptualisering, terwyl laasgenoemde die produk van spesialiste is. Dit lê ook op dieselfde baan as wetenskap.

** Moderne wetenskap verteenwoordig die moderne sekularisasie van die simboliese verwysingsraamwerk. Dit verteenwoordig ook die de-institusionalisering van simbole. 
* Kennis en waarheid het ook 'n legitimeringsfunksie - beide op kognitiewe en normatiewe vlak. Volgens Berger kan dit van alle kennis gesê word, maar is dit veral waar van geïnstitusionaliseerde kennis en van die simboliese verwysingsraamwerk. Daar is ook sprake van ' $n$ individuele legitimering. Individue vind hulle plek in terme van die simboliese verwysingsraamwerk.

** Ideologie verteenwoordig 'n gespesialiseerde geval. Dit is volgens Berger (in Wuthnow 1984:50) 'n stel idees wat die verskuilde interesse van sekere groepe in die gemeenskap legitimeer. Dit probeer gewoonlik ook inpas in die groter simboliese verwysingsraam.

** Religieuse legitimering is die duidelikste en mees effektiewe vorm daarvan. Legitimasie geskied deur sakralisasie of 'n beroep op geopenbaarde waardes. Teodiseë verteenwoordig 'n gespesialiseerde legitimeringsfunksie. Volgens Berger (in Wuthnow 1984:51) is teodiseë niks anders as die verklaring van krisisse en die verwerking en legitimering van ervarings wat daarmee gepaard gaan nie.

** Nog 'n interessante element van legitimering is die sogenaamde plausibility structure. Dit het te doen met die grense wat in die alledaagse lewe vir waarskynlikheid en aanvaarbaarheid gestel word.

Oor religie het Berger heelwat geskryf, veral oor religie in die moderne konteks. Hoewel religie 'n hoogs effektiewe vorm van institusionalisering en legitimering uitmaak, is dit in die moderne era aan die aftakelende effek van de-institusionalisering blootgestel. Godsdiens is die afgelope eeu uit verskeie belangrike geïnstitusionaliseerde lewensterreine verdryf na die private domein. Daar is baie redes hiervoor, waaronder godsdienstige pluraliteit, die impak van die kritiese wetenskap en sekularisasie (synde die desakralisering van lewensterreine). Slegs binne die private domein word nog plausibility structures aangetref wat vir geloofswaarhede voorsiening maak, en selfs hulle verkeer onder druk. Die sacred canopy het taamlik gehawend geraak.

Aan die ander kant beteken dit nie dat godsdienstige geloof en praktyk as sodanig bedreig word nie. Moderniteit kan trouens selfs gunstig blyk te wees vir godsdiens, aangesien die moderne manier van legitimering (synde 'n beroep op gespesialiseerde kundigheid) essensieel elitisties is en die gewone mense nie daardeur aangespreek word nie. Berger se beginsel dat alledaagse pragmatiese omgang met die werklikheid voorrang in werklikheidskonstruksie geniet, beteken dat die toekoms van godsdiens nie in 
die hande is van teoloë wat op verhewe en abstrakte vlak gesprek voer met verteenwoordigers van filosofie en wetenskap nie, maar dat dit by gewone godsdienstige mense berus.

Laastens is dit interessant dat hy 'n duidelike onderskeid tref tussen wetenskaplike domein en die private domein. In laasgenoemde word waardekeuses uitgeoefen wat nie in eersgenoemde toelaatbaar is nie. Hy beskou dit nie as ' $n$ skisofrenie nie, maar as die noodwendige gevolg van die dissipline en askese wat in wetenskap aanvaar moet word, maar wat ook in die gewone daaglikse en praktiese lewe oorskry moet word (Wuthnow 1984:33-34).

Michel Foucault (1926-1984), 'n Franse filosoof-skrywer in die postmoderne styl, rig hom op die strategiese en magsimplikasies van kennis en hoe dit in kultuur hanteer word. Vanweë sy Marxistiese agtergrond is hy skerp bewus van mag. Die cordrag van kennis gaan ook altyd gepaard met magsimplikasies en magsoorwegings (bewustelik of onbewustelik).

Die studente-opstande van 1968 het Foucault se standpunt oor kennis en mag versterk (kyk Wuthnow 1984:152). Hy het tot die gevolgtrekking gekom dat. die opstande die gevolg was van die massa se frustrasie met 'n sosiale stelsel wat hulle insette en deelname aan die intellektuele diskoers en aan die kennisgemeenskap blokkeer het, omdat laasgenoemde ingestel was op die beskerming van gevestigde belange. Hy het tot die oortuiging gekom dat kennis en waarheid sosiale faktore is met belangrike magsimplikasies en dat beheer daaroor deel van die magspel binne elke gemeenskap en kultuur is.

Foucault rig hom onder andere op die wetenskapsbeweging binne die Westerse samelewing en kultuur van die afgelope paar eeue. Dit word as 'n gewone sosiaalkulturele verskynsel naas ander ontleed en beskryf. Die ideologiese agtergronde en effekte daarvan word ook oorweeg. Hy toon aan hoe die verskillende spesialiteitsrigtings nie alleen die wetenskap dien nie, maar in die mate waarin dit as vakgemeenskappe georganiseer word en 'n eie tegniese jargon ontwikkel, ook as eksklusiewe belangegroepe gesien kan word wat nuwe kontoere aan die magspel in die samelewing gee.

Die konklusie kan daaruit gemaak word dat wetenskaplikes en deskundiges gesien moet word as 'n nuwe stand of klas, ' $n$ intellektuele klas wat die klerikale klas (volgens Marx se analise) se rol oorgeneem het. Hulle rol en motiewe moet dus met dieselfde kritiese houding benader word en baie van dieselfde argumente wat Marx teen die klerus aangewend het, kan op hulle ook van toepassing gemaak word. Die ironie is egter dat Marx en Foucault self aan hierdie nuwe klas behoort het. 


\section{KERK AS KULTUURVERSKYNSEL EN AS LIGGAAM VAN CHRISTUS}

Kennissosioloë, soos Berger, het in die Feuerbach-tradisie ons oë geopen vir die menslikheid van ons werklikheid, synde 'n sosiaal gekonstrueerde werklikheid. Veel dieper sny die insig dat waarheid in ' $n$ hoë mate van sosiale konsensus afhanklik is. Waarheid is dit wat deur die gemeenskap of selfs dominante belangegroepe toegelaat word om waarheid te wees. Kennis is mag. Dit beteken dat die beeld van kennis en wetenskapsontwikkeling as die resultaat van intellektuele nuuskierigheid wat in akademiese vryheid voortwoeker, in 'n hoë mate gerelativeer word. Waarheid en kennis moet ook as kulturele, sosiale en selfs politieke verskynsels bedink word.

Dat die kerk aan sosiale en kulturele kragte onderworpe is, word lank reeds begryp. Die gedagte van die inheemswording van die evangelie, kerk en teologie gee uitdrukking daaraan. Die kennissosiologie voer dié insig egter veel verder: die kerk leef in 'n sosiaal gekonstrueerde werklikheid - selfs die basiese konsepte waarmee gedink word, moet aản sosiale en kulturele kragte, ja meer nog, aan groepsbelange onderworpe geag word. Dan help dit nie om te redeneer dat die kerk 'n groot aandeel in die konstruksie van die werklikheid gehad het nie, aangesien die kerk ook as sosiale en kulturele grootheid bedink moet word.

Dit toon maar net weereens watter gevangene die mens van sy eie menslikheid is. Dit laat ' $n$ mens aan die herhalende tema van lotsgebondenheid in die Griekse tragedies dink - hoe meer verhewe die gedagtes van mense hoe duideliker kom hulle menslikheid daarin na vore. Die omgekeerde is egter ook waar: in mense se besef van hulle beperktheid gaan ' $n$ besef van transendensie skuil: Hoe meer verfynd en diepgaande die besef van kreatuurlikheid en beperktheid, hoe reikhalsender dikwels die behoefte en drang om dit te bowe te gaan.

Die evangelie wat die kerk besiel en motiveer, maak veel van die samehang tussen menslikheid en transendente goddelikheid. Sondeval is wanneer die mens self sy/haar kreatuurlikheid te bowe probeer gaan. Verlossing is wanneer hy/sy besef hoe afhanklik hy/sy van God is en sy/haar beperkte menslikheid honoreer. Jesus Christus se goddelikheid kom juis daarin na vore dat $\mathrm{Hy} \mathrm{God} \mathrm{in} \mathrm{alles} \mathrm{gehoorsaam} \mathrm{was} \mathrm{en} \mathrm{sy} \mathrm{roeping} \mathrm{as}$ Seun van die Mens volvoer het. Wanneer Karl Barth oor die totaal-andersheid van God praat, bedoel hy nie om daarmee te betoog dat God geen relevansie vir sondige mense het nie.

Dit is bekend dat Barth 'n groot waardering vir Feuerbach gehad het. Hy raai byvoorbeeld in 1922 predikante voor wie hy opgetree het, aan om pastoraal-teologiese tydskrifte te los en hulle eerder in die literatuur van Feuerbach te verdiep (Vlijm 1956: 115). Feuerbach het hom laat besef hoe menslik die mens en die wêreld van die mens is. Die menslike aard van religie en sakrale instellings en strukture het aan die lig gekom. Baie daarvan het geblyk torings van Babel te wees. Dit het die wonder van goddelike ingrype en verlossing des te skerper laat uitstaan. 
Op dieselfde wyse lei die besef van die diepgaande menslikheid van die kerk, sy godsdienstigheid en teologie nie tot uitsigloosheid of die ineenstorting van geloof nie, maar tot die besef dat geloof nie anders as kinderlik kan wees nie. Daar is uiteindelik bittermin indien enige sakrale instellings of strukture wat as steunstelsels vir die geloof kan dien. Daarom dat aan God en sy Gees alle eer toekom wat Skrif tot Woord laat word en uit sondige menswees kinders vir Homself verwek. Paulus kan in 'n ander verband aangehaal word: die taal, begrippe, idees en strukture waarmee die evangelie ontvang is, gedra en oorgedra word, is maar erdekruike wat maklik breek. Dit gaan om die inhoud en nie soseer om die houer nie. Dié onderskeid moet deurentyd in gedagte gehou word, al is dit nie altyd maklik om te verstaan waarop dit aankom nie.

Hoewel Barth religie as kultuurverskynsel hanteer, dit 'n geestelike toring van Babel noem en die gedagte verwerp dat dit 'n praeparatio evangelica kan wees, is dit van betekenis dat sy stelling dat die openbaring religie ophef, nie net in een sin verstaan moet word nie.

Wij vonden immers dat de religie ook 'aufgehoben' kan worden in de zin van 'wohlaufgehoben', dat de openbaring niet buiten de religie omgaat, maar in de wereld der menselijke religie ingaat. Wij vonden de gedachte dat de religie een reactie is op een handelen Gods, ja, dat de religie een gevolg is van de toorn Gods, die de mens aan zichself overgeeft. Wij hoorden Barth spreken over de religie als over die lege huls van het verbond.

(Vlijm 1956:116vv)

Vlijm (1956) het reeds in die vyftigerjare aangetoon dat Barth se standpunt oor religie eensydig negatief deur persone soos $\mathrm{H}$ Kraemer en M Schlunk weergegee is. Bonhöffer se standpunt oor 'n a-religieuse Christendom is waarskynlik ook op 'n eensydige verstaan van Barth gebaseer.

Wij beginnen met een zin, die bijzonder veel gelijkenis vertoont met een zin uit de KD 1,2. Daar heet het: 'Die Offenbarung ist die Aufhebung der Religion, wie die Religion die Aufhebung der Offenbarung ist' (KD I, 2:331). In de Römerbrief lezen wij: 'Das Evangelium ist die Aufhebung der Kirche, wie die Kirche die Aufhebung des Evangelismus ist'. ( $\mathrm{Rbr} 317$ ). Tot goed verstaan is het nodig te noteren dat Barth met 'Kirche' niet bedoelt het liggaam van Christus, maar de źichtbare kerk, die in zijn uiterlijk waarneembare gedaante niet wezenlijk verschilt van 
allerlei andere religieuze gemeenschappen. 'Kirche' kan weergegeven worden met 'die Welt der Religion, wie sie in der Geschichte ... in die Erscheinung tritt'. (Rbr 316). Deze Kirche is overal waar het Evangelie ist. 'Es gibt im Munde des Menschen keine reine, keine unkirchliche Verkündigung des Evangeliums'. Deze onreinheid, deze 'religieuse besmetting' van het Evangelie heeft plaats, omdat 'iemand ernsthaf von Gott reden kann, ohne gleichzeitig in stärkster Weise sich selbst mitzuteilen und durch-zusetzen' (Rbr 317). Er is geen mogelijkheid deze ergernis te ontgaan. De verkondigers van het Evangelie kunnen niet anders dan solidair zijn met de wêreld der religie, dan solidair zij met de zonde. Zij kunnen niet anders.

... Men kan uit bovenstaande in ieder geval verstaan, dat er volgens Barth een relatie is tussen de religie en het Evangelie en omgekeerd. De religie kan niet bestaan zonder de openbaring, en de openbaring bestaat niet zonder de religie.

(Vlijm 1956:95)

Die kerk het dus ook 'n dubbele natuur: enersyds as religie of kultuurverskynsel en andersyds as liggaam van Christus. Dit is maar net nog ' $n$ manier om te sê dat die kerk in die wêreld is, maar nie van die wêreld nie. Voortgaande geloof en die aanvaarding van die kerk as liggaam van Christus, en die tegelyke aanvaarding van die diepgaande menslike aspekte daarvan, is slegs moontlik deur 'n na-kritiese naïwiteit. Na-krities beteken in hierdie geval nie die uitskakeling van kritiek nie, maar kritiek op 'n ander wyse - meer barmhartig, hoewel nie minder skerp nie.

\section{KULTUUR, VOLK EN VOLKSKERK}

R D Coertze definieer volk (of etnos) soos volg:

'n Volk is ' $n$ groep mense wat ' $n$ eenheid vorm op grond van die besit van 'n eenvormige kultuur of lewenswyse wat deur 'n lang proses van samewoning, ondertrouing en kultuuroordrag na opeenvolgende generasies verwerf is.

(Coertze 1980:159) 
Oor sy definisie lewer hy onder andere die volgende kommentaar:

(a) 'n Volk is 'n groep mense wat uit hulleself 'n eenheid met 'n besondere identiteit vorm .... Die volk is van sy eie identiteit bewus. Die feit dat 'n volk 'n afsonderlike identiteit vertoon, word ook deur ander volke met wie hulle kontak het, erken.

(b) Dit is dus duidelik dat die blote samewoning van mense in dieselfde gebied nie as sodanig genoeg is om die besondere verbondenheid wat vir aanhorigheid aan dieselfde volk nodig is, te bewerkstellig nie. Die wat saamwoon, moet ook vanweë lotsverbondenheid ondertrou en die verband moet deur die opvoeding van verskillende opeenvolgende geslagte 'n permanente karakter vertoon.

(Coertze 1980:159)

Verder sê Coertze:

Kontak tussen kulture beteken in elke geval ook kontak tussen die mense wat hierdie kulture dra. Wanneer mense met mekaar in langdurige en direkte kontak tree, gaan dit nie meer slegs om kulturele beïnvloeding en moontlik samegroeiing nie, maar ook om die samegroeiing van die draers van hierdie kulture.

(Coertze 1980:162)

Etnos word in 'n latere werk soos volg verduidelik:

('n) Ontiese bestaanseenheid van die mens; 'n groep mense wat 'n eenheid vorm op grond van ' $n$ werklike of vermeende gemeenskaplike identiteitsbesef en lewenswyse wat oor 'n lang periode van samewoning ontwikkel is en deur andere erken word.

(Coertze 1996:75)

Oor identiteitsbesef word die volgende opmerking gemaak: 
(Besef van eie identiteit) hang gewoonlik saam met die aanduiding van 'n eie naam, die beklemtoning van gemeenskaplike kultuurkenmerke (byvoorbeeld taal en religie), historiese wording en selfs rassekenmerke.

(Coertze 1996:76)

Berger en sy medestander, Thomas Luckmann, sien identiteit as iets wat in die dialektiese verhouding tussen individu en gemeenskap ontstaan en voortdurend opnuut vorm aanneem (Berger 1967:174). Hulle dink dus in terme van individuele identiteit. Daar is egter ook sprake van 'n super-identiteit wat gegrond is in 'n kosmiese werklikheid wat alledaagse veranderlikes en marginale ervarings transendeer (Berger 1967:118). Dié kosmiese werklikheid is die simboliese universele verwysingsraamwerk.

Identiteit is nie 'n vaste gegewenheid nie, maar moet voortdurend uitgebou word, teen aanslae verdedig of versterk word, of in die lig van veranderende omstandighede of nuwe uitdagings aangepas word. Identiteit kan verdwyn - geleidelik, soos in die geval van ' $n$ immigrantegemeenskap wat oor generasies assimileer, of vinnig, soos in die geval van verskeie sentraal-Amerikaanse volke of gemeenskappe wat voor die aanslae van die Spaanse veroweraars in duie gestort het.

Die sosioloog, Hans Mol, het uitgebreid oor identiteit geskryf. In 'n baanbrekerswerk waarin hy die verband tussen identiteit en godsdiens verken (Mol 1976), wys hy by herhaling daarop dat gemeenskappe of groepe met ' $n$ godsdienstige inslag baie beter daarin slaag om hulle identiteit (gemeenskaplik en individueel) te handhaaf as gesekulariseerde groepe.

Sacralization is the inevitable process that safeguards identity when it is endangered by the disadvantages of the infinite adaptability of symbolsystems. Sacralization protects identity, a system of meaning, or a definition of reality, and modifies, obstructs or (if necessary) legitimates change .... The widespread conclusion has been drawn that the sacred is on its way out. I do not think this is so. Sacralization processes may be interrupted and prevented from maturing, but they are not disappearing: they appear to be as viable as ever.

(Mol 1976:6, 7)

In 'n studie van Lewins (1978) word die verband tussen godsdiens en etniese identiteit nagegaan. Hy toon aan hoe die Rooms-Katolieke Kerk etniese minderhede in Australië wat die nasate van immigrante is, gehelp het om hulle etniese identiteit in stand te hou 
of selfs ' $n$ nuwe identiteit te ontwikkel. In die geval van Italiaanse immigrante het die kerk hulle deur die instelling van spesiale misdienste in Italiaans gehelp om tot 'n enkele Italiaanse groep te konsolideer, alhoewel hulle in hulle land van herkoms nie geneig was om so oor hulleself te dink nie. Die kerk het dus vir hierdie groep 'n brug geskep waarmee hulle die plurale Australiese samelewing kan betree, sonder om alles wat hulle vantevore was prys te gee.

In die geval van persone van Oekrainiese afkoms is ' $n$ ander verskynsel waargeneem. Vanweë hulle lang geskiedenis van onderdrukking deur die Turke en ontkenning deur Russiese owerhede is daar by Oekrainiërs wêreldwyd 'n skerp etniese bewussyn teenwoordig. Kerk is vir hulle ' $n$ belangrike simbool van etnisiteit, maar kerklike lidmaatskap is steeds ondergeskik aan etniese verbondenheid. Dit kan daarvan afgelei word dat Oekrainiese Rooms-Katolieke erken dat hulle minder met Australiese RoomsKatolieke in gemeen het as met Oekrainiërs wat aan die Ortodokse Kerk behoort. 'This relationship of national and religious elements in Ukrainian ethnic identity has been described as the "sanctification of ethnicity" and the "ethnization of religion"' (Lewins 1978:29). Die verskil met die Italiaanse groep het daarin gelê dat die meeste Oekraïniërs steeds die droom van 'n terugkeer na hulle tuisland gekoester het en nie regtig van plan was om deel van die Australiese samelewing te word nie.

Die verband tussen etniese identiteit en kerk word lank reeds in die volkskerkgedagte van die Nederduitsch Hervormde Kerk erken. Uitgaande van die verbond groei die kerk via gesinne die volk in.

Om by die ganse mensdom te kom, gaan die kerk in elke geleding van die mensdom in. Die volksgeledinge van die mensdom vorm organiese en omvattende lewenseenhede, gevoed en opgebou deur gesinne waarbinne kinders weens die ouers se verbondenheid met Christus ook in die verbond ingesluit is (Hand 2:39; 1 Kor 7:12-14). Daarom behoort die kinders binne die verbond gedoop te wees.

Verbondskerk wat dus kennis dra van gesinne binne die verbond, van gesinne waaruit ' $n$ volk basies opgebou word, is in soverre reeds volkskerk.

... Hoewel die volkskerk nie die Bybelse uitverkiesing en bekering buite rekening laat nie, is dit tog in hierdie opsig die derde opsie teenoor die historiese metodisme en die neo-Calvinisme.

(Van der Westhuizen 1990:65vv) 
In die uitvoerige ekklesiologiese denke wat reeds in die Nederduitsch Hervormde Kerk aan die volkskerk gewy is, is telkens en by herhaling afgegrens teen die gedagtes dat volkskerk ' $n$ nasionale of openbare instelling is, besitting van die volk is, afhanklik is van etnisiteit, volledig met volksbelange te identifiseer is en dies meer. Van der Westhuizen (1990:77) sê hieroor ook die volgende:

Daar is een ware kerk, die liggaam van Christus, die volk van die ewige Koning. Maar daar is baie nasionale volke en konings en owerhede. Die één kerkvolk is dus in die gestaltes van baie volkskerke versprei.

Die kerk van die Here is die volk van die Here. Die kerk is volk. Daarom volkskerk. Kerk en nasionale volk val nooit in ons gebroke bedeling saam nie. Met volkskerk word bedoel dat die kerk as volk van God in 'n volk moet lewe.

Die sin van volkskerk lê dus in 'n kerstende teenwoordigheid in die volk.

Die intranasionale volkskerk wil in die volksbewussyn kerstenend ingaan. Die volkskerk wil hê dat die kerk so in elke volk se diepste vesels ingaan. Almal in die volkshuis moet bereik word. Die hele lewe van almal moet gekersten word .... Wat gaan die kerk in die volksbewussyn doen indien die kerk daar nie Jesus Christus gaan bely nie, dit wil sê kerstenend gaan wees nie? Indien die kerk iets anders wil gaan doen, is hy nie meer kerk nie.

Tog blyk dit dat daar 'n ongemaklikheid bestaan oor die verhouding volkskerkvolksidentiteit. Hieroor skryf Botha (1989:44):

Hierdie eiendomlikhede (van die Afrikanervolk) vorm dan die omgewing waarvan die Ned Herv Kerk die kleur aanneem, omdat hy as volkskerk so nou met hierdie volk verbind was, is en wil wees. Hierdie eiendomlikhede medebepaal ook die Ned Herv Kerk .... Die Kerk sien dit daarom ook nie as onskriftuurlik 'as hy die eiendomlike wat God aan die volk, uiterlik en innerlik, gegee het wil bewaar, beskerm en bestendig nie' (Herderlike Skrywe 1973:4). 
Om te praat van eiendomlikhede wat God aan die Afrikanervolk gegee het, is om uit te gaan van ' $n$ historiese openbaringsbeginsel. Ten spyte van die verweer van die Herderlike Skrywe loop dit ook die ernstige risiko van natuurlike teologie. Buitendien, wie gaan vandag besluit wat as Godgegewe Afrikaner-eiendomlikheid beskou moet word ...? Van der Westhuizen (in Botha 1989:74) skryf hieroor ook die volgende:

Die taak van die volkskerk is moeiliker maar veiliger as die van 'n vrye of vryblywende kerk. Dit is moeiliker omdat sy taak as uitverkiesingsinstrument suiwer Bybels bepaal moet bly. Hy mag nie met volksinhoude die Bybelse inhoud van sy taak vervang nie. Hierdie risiko bestaan juis omdat hy in die midde van die volk kan vervolk. Dit is dieselfde gevaar dat die kerk in die wêreld kan verwêreld. Om hierdie rede mag die kerk hom tog nie uit die wêreld of uit die volk onttrek nie.

Hierdie risiko moet die kerk loop en die moeilikheid om vir jou eie mense, jou eie volk, jou eie wêreld die kritiese, herskenpende, omvormende en kerstenende Woord van God te spreek, oorwin. Dit het die profete en apostels gedoen - selfs in die aangesig van vervolging, gevangenskap, kruisiging, onthoofding, steniging en so meer.

Dit kom dus daarop neer dat die volkskerk ' $n$ pastorale en profetiese roi in en teenoor die volk moet inneem. Die kerk moet altyd daarteen waak dat dit as gevangene deur volksgevoel en -sentimente weggevoer word. Dit is egter nie net die volkskerk wat hierdie risiko loop nie, soos ons hierbo gesien het.

Om terug te keer na die vraag van die vier-en-sestigste Algemene Kerkvergadering: Die kerk het dan 'n pastorale én profetiese taak teenoor die volk, kultuur en selfs volkseie. Dit beteken dat die Nederduitsch Hervormde Kerk, as dit kerk van Christus wil wees, nie net moet begelei nie, maar ook bereid moet wees om standpunt teenoor die volk in te neem, veral as dit duidelik word dat bepaalde sentimente uit selfsug gebore is of die waarheid en geregtigheid in gedrang kom. Soos mense is rolke sondige groothede en daarom geneig om hulle eie belang voorop te stel. Soms kan dit vir die kerk selfs moeilik wees om die waarheid en geregtigheid te onderskei, omdat dit ingetrek word in die werklikheidskonstruksie en die waarheidskonsensus van die volk. Daarom is dit belangrik dat die volkskerk altyd sal onthou dat dit eintlik katolieke kerk is. Die getuienis van die groter kerklike gemeenskap wat wêreld en eeue omspan, moet ook aangehoor en in aanmerking geneem word. 
Vanweë die natuurlike aantrekkingskrag tussen gemeenskap, kultuurgroep of volk, enersyds, en godsdiens of kerk, andersyds, hou kerklike betrokkenheid by die volkseie of volksidentiteit risiko's in wat nie ligtelik opgeneem kan word nie. Klanke van volksteologie wat kort-kort gehoor word en waarvan daar in elk geval talryke voorbeelde in die geskiedenis van die Afrikaner is, is waarskuwings dat dit nie ' $n$ ydele vrees is nie. Moet die Nederduitsch Hervormde Kerk verantwoordelikheid anvaar vir die instandhouding van volksidentiteit, byvoorbeeld deur bepaalde ideale te sakraliseer en te legitimeer? Dit kan nie. Deur so 'n optrede word die kerk sonder remme op die gevaarlike weg van burgerlike godsdiens geplaas.

\section{BURGERLIKE GODSDIENS EN BURGERLIKE IDEOLOGIE}

Burgerlike godsdiens kom as begrip gedurende die sestigerjare na vore na aanleiding van 'n pleidooi deur Robert Bellah vir 'n 'Amerikaanse burgerlike godsdiens' om daarmee die Amerikaanse publiek saam te snoer. Die term self gaan so ver terug as $\mathbf{J} \mathbf{J}$ Rousseau, maar in die moderne sin veronderstel dit die hele ontwikkeling van Godsdienssosiologie sedert E Durkheim (vgl Van der Merwe 1982).

Verskeie studies is hierna geskryf wat die verskynsel in verskillende kontekste beskryf (vgl byvoorbeeld Cuddihy 1978 en Moodie 1978). Daar is aangetoon hoe daar in die openbare domein ' $n$ konsensus tot stand kom oor hoe sekere gebeurtenisse in die verlede verstaan moet word en simbole in die hede as eenheidsimbole opgeneem kan word. Dit vorm dan die simboliese verwysingsraamwerk van 'n algemeen, publiekaanvaarde werklikheidskonstruksie. In die geval van die VSA is dit onderbou deur 'n vae konglomoraat van Protestantse, Rooms-Katolieke en Joodse godsdienstige sentimente. In Suid-Afrika was dit volgens Moodie (1978) die kerke van die Afrikaner, soos verteenwoordig deur sy predikante en teoloë in die Broederbond, wat dié rugsteun getiad het.

Verskeie studies oor burgerlike godsdiens in Suid-Afrika het die fout gemaak om dié verskynsel slegs by die Afrikanervolk te vind, waarskynlik omdat die politieke bedeling op daardie stadium onder Afrikanerbeheer was. In der waarheid is dit egter 'n verskynsel wat in 'n mindere of meerdere mate in alle gemeenskappe en samelewings voorkom.

Aan die ander kant kan geen kerk dit bekostig om die aanklag van burgerlike godsdiens ligtelik op te neem nie, veral wanneer Moodie (1978:204) Afrikaanse burgerlike godsdiens 'n 'Calvinist heresy' noem en aantoon hoe dit op volksteologie of te wel natuurlike teologie gebaseer is. Dit was beskuldigings wat seergemaak het, omdat dit nie ontken kon word dat dit ten spyte van al die oordrywing en verdraaiing heelwat waarheid ingehou het nie. Hopelik is ons vandag meer sensitief vir die gevaar van burgerlike godsdiens. 
Daar is egter 'n aanverwante verskynsel waarop ook gelet moet word, naamlik burgerlike ideologie.

In elke samelewing en kultuur word waarheid en kennis beheer deur wat Berger ' $\mathrm{n}$ 'plausibility structure' noem. Newbigin beskryf dit soos volg:

... 'Plausibility structures', patterns of belief and practice accepted within a given society, which determine which beliefs are plausible to its members and which are not .... Thus when, in any society a belief is held to be 'reasonable', this is a judgment made on the basis of the reigning plausibility structure.

(Newbigin 1991:8)

Hy gaan hierna voort en toon aan hoe dit selfs in die wetenskaplike gemeenskap toepassing vind. Hy beskryf hoe hierdie gemeenskap hom vrywillig aan 'n gesag onderwerp wat saamhang met die gangbare wetenskapsparadigma.

The authority of the tradition is maintained by the community of scientists as a whole. This community is held together by the free assent of its members. But it is, nonetheless, a powerful authority. It is exercised in practice by those who determine which articles will be accepted for publication in scientific journals and which rejected, and by those who determine appointments to teaching and research posts in universities and other institutions. There is no appeal within the scientific community against this authority, and any appeal outside falls on deaf ears.

(Newbigin 1991:46)

Wat so 'n paradigma presies behels, is nie maklik om te sê nie. Dit is 'n vae konsensus oor hoe die werklikheid verstaan en benader moet word. Ten spyte van die vaagheid is wetenskaplikes bereid om hulle aan die 'plausibility structure' wat daarvan afgelei word, te onderwerp, omdat hulle in die geldigheid daarvan glo. Die indruk van oortuiging en sekerheid wat wetenskaplikes dikwels skep, is dus in die laaste instansie in 'n vorm van geloof gefundeer.

In 'n gesekulariseerde samelewing en kultuur, soos dié waarvan die blankes in Suid-Afrika deel is, funksioneer natuurlik dergelike strukture van aanvaarbaarheid. Dié strukture ontsê bepaalde Christelike geloofsaannames aanvaarbaarheid, maar gaan self op 'n vae 'wetenskaplik-gekonstrueerde', antisupranaturalistiese werklikheid terug. 
Die grondmite van die kultuur is 'die wetenskap'. Aangesien legitimering nie deur religie of sakralisering plaasvind nie, kan moontlik van ideologie gepraat word - 'n ideologie wat ook die sekulêre strukture van aanvaarbaarheid legitimeer en daarom burgerlike ideologie.

Newbigin wil Westerse Christene daartoe oproep om die grondslae en aard van die kultuur van hulle tyd krities te oordink en waar nodig te ontmitologiseer. Hy daag gelowiges uit om die evangelie met groter selfvertroue uit te leef en uit te dra, en hulle nie deur aannames wat die eietydse kultuur of sosiale konsensus onderbou en wat self na 'n vorm van geloof teruggaan, te laat inhibeer nie.

\section{TEN SLOTTE}

Die kerk is op 'n hoogs intieme wyse met kultuur verweef en kan net so min daaraan ontstrengel word as wat mense van hulle eie skaduwee kan ontsnap. Saam met Barth moet die goddelike aard van die kerk se roeping bely word, ten spyte daarvan dat die kerk wel as religie en kultuurverskynsel onderken word.

Die roeping van die kerk teenoor volk en kultuur is apostolêr en profeties, hoe moeilik dit ook mag wees.

\section{Literatuurverwysings}

Berger, P L \& Luckmann, T 1967. The social construction of reality. London: Penquin Press.

Botha, S J (red) 1989. Belydende volkskerk. Pretoria: Kital.

Coertze, P J (red) 1961. Inleiding tot die Algemene Volkekunde. Tweede druk. Johannesburg: Voortrekkerpers.

Coertze, P J \& Coertze, R D 1996. Verklarende vakwoordeboek vir Antropologie en Argeologie. Pretoria: R D Coertze.

Coertze, R D 1980. Memorandum oor die Volkekundige implikasies van Artikel III van die Kerkwet, in Lidmaatskap in die Nederduitsch Hervormde Kerk van Afrika: Studie oor Artikel III van die Kerkwet. Ongepubliseerde bundel, pp 156-168.

Cuddihy, J M 1978. No offense: Civil religion and Protestant taste. New York: Seabury Press.

Die kerk in die wêreld: 'n Bundel opstelle aangebied aan prof dr A D Pont by sy 25 jarige ampsjubileum. 1982. Pretoria: Kital. (Aangehaal as Die kerk 1982.)

Geertz, C 1973. Interpretation of cultures. New York: Basic Books, aangehaal in Shweder 1984.

LeVine, R A 1984. Properties of culture - an ethnographic view, in Shweder 1984: 67-87. 
Lewins, F W 1978. Religion and ethnic identity, in Mol 1978: 19-38.

Mol, H 1976. Identity and the sacred: A sketch for a new social-scienific theory of religion. Oxford: Basil Blackwell.

Mol, H (ed) 1978. Identity and religion: International, cross-cultural approaches. London: Beverly Hills. (SAGE Publications.)

Moodie, T D 1978. The Afrikaner civil religion, in Mol 1978: 203-228.

Newbigin, L 1991. The gospel in a pluralist society. 2nd ed. Geneva: WCC Publications.

Nederduitsch Hervormde Kerk 1995. Besluitebundel vir die 64ste Algemene Kerkvergadering van die Nederduitsch Hervormde Kerk van Afrika. Ongepubliseerd. (Aangehaal as AKV 1995.)

Shweder, R A \& LeVine, R A 1984. Culture theory: Essays on mind, self, and emotion. New York: Cambridge Universiteit Press. (Aangehaal as Shweder 1984.)

Van der Merwe, P J 1982. 'Burgerlike godsdiens' in Suid-Afrikaanse konteks - teologies én godsdienswetenskaplik oorweeg, in Die kerk 1982: 193-203.

Van der 'Nesthuizen, H G 1990. Kerk en kerstening. Pretoria: Kital.

Vlijm, J M 1956. Het religiebegrip van Karl Barth: Een onderzoek naar de betekenis van Barths religie-begrip voor de discussie over de niet-Christelijke godsdiensten in de Protestantse zending. 's-Gravenhage: Uitgeverij Van Keulen NV.

Wuthnow, $\mathrm{R}$ et al 1984. Cultural analysis: The work of Peter L Berger, Mary Douglas, Michel Foucault, and Juergen Habermas. Boston: Routledge \& Kegan Paul. 